\title{
The Effect of Initial State Error for Nonlinear Systems with Delay via Iterative Learning Control
}

\author{
Zhang Qunli \\ Department of Mathematics, Heze University, Heze, Shandong 274015, China \\ Correspondence should be addressed to Zhang Qunli; qunli-zhang@126.com
}

Received 6 February 2016; Accepted 23 March 2016

Academic Editor: Ming Mei

Copyright (C) 2016 Zhang Qunli. This is an open access article distributed under the Creative Commons Attribution License, which permits unrestricted use, distribution, and reproduction in any medium, provided the original work is properly cited.

An iterative learning control problem for nonlinear systems with delays is studied in detail in this paper. By introducing the $\lambda$-norm and being inspired by retarded Gronwall-like inequality, the novel sufficient conditions for robust convergence of the tracking error, whose initial states are not zero, with time delays are obtained. Finally, simulation example is given to illustrate the effectiveness of the proposed method.

\section{Introduction}

Since iterative learning control is proposed by Arimoto et al. in 1984 (see [1]), this feedforward control approach has become a major research area in recent years. Iterative learning control, which belongs to the intelligent control methodology, is an approach for fully utilizing the previous control information and improving the transient performance of studied systems that is suitable for repetitive movements. Its goal is to achieve full range of tracking tasks on finite interval (see [2-14]).

In practice, the control problem of systems with delays has always been an interesting research, since time delay can be often encountered in a wide range, such as aircraft systems, turbojet engines, microwave oscillators, nuclear reactors, and chemical processes. The existence of time delay in a system may degrade the control performance and even at worst may become a source of instability. Stabilization problem of control systems with delay has received much attention for several decades and some research results have been reported in the literature (see $[3,11,13,15-23])$. However, only a few results are available for nonlinear systems, combining with the iterative learning control items, with time delays [11, 2426]. In this paper, under the case that the $k$ th iterative state vector $x_{k}(t)$ is different from the $(k+1)$ th iterative state vector $x_{k+1}(t)$, that is, $x_{k+1}(t)-x_{k}(t) \neq 0$, the iterative learning controller of nonlinear time-delayed systems is designed by using $\lambda$-norm and retarded Gronwall-like inequality.
Before ending this section, it is worth pointing out the main contributions of this paper as follows.

(1) The iterative learning control problem for nonlinear systems with delays is investigated. That is, we consider the system

$$
\dot{x}_{k}(t)=f\left(t, x_{k}(t)\right)+g\left(t, x_{k}(t-\tau)\right)+u_{k}(t),
$$

which is different from the mentioned system

$$
\dot{x}_{k}(t)=f\left(t, x_{k}(t)\right)+u_{k}(t)
$$

in past literature.

(2) Based on retarded Gronwall-like inequality and the convergence of tracking error $e_{k}(t)=y_{d}(t)-y_{k}(t)$, the practical output $y_{k}(t)$ is determinate by the previous iterative learning control information $x_{k}(t), u_{k}(t), \varphi_{k, h}(t)$.

\section{Preliminaries}

Throughout this paper, the 2-norm for the $n$-dimensional vector $x=\left(x_{1}, x_{2}, \ldots, x_{n}\right)^{T}$ is defined as $\|x\|=\left(\sum_{i=1}^{n} x_{i}^{2}\right)^{1 / 2}$, while the $\lambda$-norm for a function is defined as $\|\cdot\|_{\lambda}=$ $\sup _{t \in[0, T]}\left\{e^{-\lambda t}\|\cdot\|\right\}$, where the superscript $T$ represents the transpose and $\lambda>0$. I and 0 represent the identity matrix and a zero matrix, respectively. 
Lemma 1 (see [10, 27]). Consider

$$
\sup _{t \in[0, T]}\left(e^{-\lambda t} \int_{0}^{t}\|x(\tau)\| d \tau\right) \leq \frac{1}{\lambda}\|x(t)\|_{\lambda} .
$$

Lemma 2 (see [28] retarded Gronwall-like inequality). Consider such an inequality

$$
u(t) \leq a(t)+\sum_{i=1}^{n} \int_{b_{i}\left(t_{0}\right)}^{b_{i}(t)} f_{i}(t, s) w_{i}(u(s)) d s,
$$

$$
t_{0} \leq t<t_{1}
$$

and suppose that

(1) all $w_{i}(i=1,2, \ldots, n)$ are continuous and nondecreasing functions on $[0,+\infty)$ and are positive on $(0,+\infty)$ such that $w_{1} \propto w_{2} \propto \cdots \propto w_{n}$;

(2) $a(t)$ is continuously differentiable in $t$ and nonnegative on $\left[t_{0}, t_{1}\right)$, where $t_{0}, t_{1}$ are constants and $t_{0}<t_{1}$;

(3) all $b_{i}:\left[t_{0}, t_{1}\right) \rightarrow\left[t_{0}, t_{1}\right)(i=1,2, \ldots, n)$ are continuously differentiable and nondecreasing such that $b_{i}(t) \leq t$ on $\left[t_{0}, t_{1}\right)$;

(4) all $f_{i}(t, s), i=1,2, \ldots, n$, are continuous and nonnegative functions on $\left[t_{0}, t_{1}\right) \times\left[t_{0}, t_{1}\right)$.

Take the notation $W_{i}\left(s, s_{0}\right):=\int_{s_{0}}^{s}\left(d z / w_{i}(z)\right)$ for $s>0$, where $s_{0}>0$ is a given constant. It is denoted by $W_{i}(s)$ simply when there is no confusion. If $u(t)$ is a continuous and nonnegative function on $\left[t_{0}, t\right)$ satisfying (4), then

$$
u(t) \leq W_{n}^{-1}\left[W_{n}\left(r_{n}(t)\right)+\int_{b_{n}\left(t_{0}\right)}^{b_{n}(t)} \max _{t_{0} \leq \tau<t} f_{n}(\tau, s) d s\right]
$$

$$
t_{0} \leq t \leq T
$$

where $r_{n}(t)$ is determined recursively by

$$
\begin{aligned}
& r_{1}(t):=a\left(t_{0}\right)+\int_{t_{0}}^{t}\left|a^{\prime}(s)\right| d s, \\
& r_{i+1}(t):=W_{i}^{-1}\left[W_{i}\left(r_{i}(t)\right)+\int_{b_{n}\left(t_{0}\right)}^{b_{n}(t)} \max _{t_{0} \leq \tau<t} f_{n}(\tau, s) d s\right], \\
& i=1,2, \ldots, n-1 ;
\end{aligned}
$$

$T<t_{1}$ and $T$ is the largest number such that

$$
\begin{array}{r}
W_{i}\left(r_{i}(T)\right)+\int_{b_{n}\left(t_{0}\right)}^{b_{n}(T)} \max _{t_{0} \leq \tau<T} f_{n}(\tau, s) d s \leq \int_{s_{0}}^{+\infty} \frac{d z}{w_{i}(z)}, \\
i=1,2, \ldots, n .
\end{array}
$$

\section{Main Results}

Consider the following system with time delay:

$$
\begin{aligned}
\dot{x}_{k}(t)= & f\left(t, x_{k}(t)\right)+g\left(t, x_{k}(t-\tau)\right)+u_{k}(t), \\
u_{k+1}(t)= & u_{k}(t)+M e_{k}(t) \\
& -\psi_{k, h}(t)\left(x_{k+1}(0)-x_{k}(0)\right), \\
y_{k}(t)= & C x_{k}(t)+D u_{k}(t)-\varphi_{k, h}(t), \\
\varphi_{k+1, h}(t)= & \varphi_{k, h}(t)-D \psi_{k, h}(t)\left(x_{k+1}(0)-x_{k}(0)\right),
\end{aligned}
$$

where $x_{k}(t) \in R^{n}, y_{k}(t) \in R^{n}$, and $u_{k}(t) \in R^{n}$ are the state vector, output vector, and input vector, respectively. $k$ is the number of iterations, $k \in\{1,2,3, \ldots\}$ and $t \in[0, T]$. $\int_{0}^{t} \psi_{k, h}(\theta) d \theta=1,(t \geq h), M, C, D$ are real constant matrices; $e_{k}(t)=y_{d}(t)-y_{k}(t), y_{d}(t)$ is a reference output.

Suppose that there exist the bounded constants $l_{f}>0$ and $l_{g}>0$ such that

$$
\begin{aligned}
& \left\|f\left(t, x_{k+1}(t)\right)-f\left(t, x_{k}(t)\right)\right\| \leq l_{f}\left\|x_{k+1}(t)-x_{k}(t)\right\|, \\
& \left\|g\left(t, x_{k+1}(t-\tau)\right)-g\left(t, x_{k}(t-\tau)\right)\right\| \\
& \quad \leq l_{g}\left\|x_{k+1}(t-\tau)-x_{k}(t-\tau)\right\| .
\end{aligned}
$$

Theorem 3. For system (8) and a given reference $y_{d}(t)$, if there exist matrices $M, C, D$ and functions $\psi_{k, h}(t)$ and $\varphi_{k, h}(t)$ such that

$$
\|I-D M\| \leq \rho<1
$$

where $\rho$ is a constant, then system (8) with the iterative learning control law can guarantee that $\left\|y_{k}(t)-y_{d}(t)\right\|$ is bounded but $y_{k}(t)$ cannot track $y_{d}(t)$ on $t \in[0, h]$ and $\lim _{k \rightarrow \infty} y_{k}(t)=y_{d}(t)$ on $t \in[h, T]$ for arbitrary initial state $x_{k}(0)$.

Proof. It is easy to know that, for any $t \in[h, T]$,

$$
\begin{aligned}
x_{k+1}( & t)-x_{k}(t) \\
= & \int_{0}^{t}\left(\dot{x}_{k+1}(\theta)-\dot{x}_{k}(\theta)\right) d \theta+x_{k+1}(0)-x_{k}(0) \\
= & \int_{0}^{t}\left(f\left(\theta, x_{k+1}(\theta)\right)-f\left(\theta, x_{k}(\theta)\right)\right) d \theta \\
& +\int_{0}^{t}\left(g\left(\theta, x_{k+1}(\theta-\tau)\right)-g\left(\theta, x_{k}(\theta-\tau)\right)\right) d \theta \\
& +\int_{0}^{t}\left(u_{k+1}(\theta)-u_{k}(\theta)\right) d \theta+x_{k+1}(0)-x_{k}(0) \\
= & \int_{0}^{t}\left(f\left(\theta, x_{k+1}(\theta)\right)-f\left(\theta, x_{k}(\theta)\right)\right) d \theta \\
& +\int_{0}^{t}\left(g\left(\theta, x_{k+1}(\theta-\tau)\right)-g\left(\theta, x_{k}(\theta-\tau)\right)\right) d \theta \\
& +\int_{0}^{t} M e_{k}(\theta) d \theta
\end{aligned}
$$




$$
\begin{aligned}
& -\left(x_{k+1}(0)-x_{k}(0)\right)\left(\int_{0}^{t} \psi_{k, h}(\theta) d \theta-1\right) \\
= & \int_{0}^{t}\left(f\left(\theta, x_{k+1}(\theta)\right)-f\left(\theta, x_{k}(\theta)\right)\right) d \theta \\
& +\int_{0}^{t}\left(g\left(\theta, x_{k+1}(\theta-\tau)\right)-g\left(\theta, x_{k}(\theta-\tau)\right)\right) d \theta \\
& +\int_{0}^{t} M e_{k}(\theta) d \theta .
\end{aligned}
$$

So we obtain from condition (9)

$$
\begin{aligned}
\left\|x_{k+1}(t)-x_{k}(t)\right\| \leq & l_{f} \int_{0}^{t}\left\|x_{k+1}(\theta)-x_{k}(\theta)\right\| d \theta \\
& +l_{g} \int_{0-\tau}^{t-\tau}\left\|x_{k+1}(\theta)-x_{k}(\theta)\right\| d \theta \\
& +\int_{0}^{t}\|M\|\left\|e_{k}(\theta)\right\| d \theta .
\end{aligned}
$$

In this paper, we use Lemma 2. Taking $t_{0}=0, b_{1}(t)=t$, $b_{2}(t)=t-\tau, a(t)=\int_{0}^{t}\|M\|\left\|e_{k}(\theta)\right\| d \theta, W_{1}(s)=l_{f} \int_{1}^{s}(d z / z)=$ $l_{f} \ln s$, and $W_{2}(s)=l_{g} \int_{1}^{s}(d z / z)=l_{g} \ln s$, then $r_{1}(t)=$ $\int_{0}^{t}\|M\|\left\|e_{k}(\theta)\right\| d \theta$ and $r_{2}(t)=\exp \left[\ln \left(\int_{0}^{t}\|M\|\left\|e_{k}(\theta)\right\| d \theta\right)+\right.$ $\left.\int_{0}^{t}\left(l_{g} / l_{f}\right) d \theta\right]=e^{\left(l_{g} / l_{f}\right) t} \cdot \int_{0}^{t}\|M\|\left\|e_{k}(\theta)\right\| d \theta$. So we have $\| x_{k+1}(t)-$ $x_{k}(t) \| \leq \exp \left[\ln \left(e^{\left(l_{g} / l_{f}\right) t} \int_{0}^{t}\|M\|\left\|e_{k}(\theta)\right\| d \theta\right)+\int_{0-\tau}^{t-\tau} d \theta\right]=$ $e^{\left(1+l_{g} / l_{f}\right) t} \cdot \int_{0}^{t}\|M\|\left\|e_{k}(\theta)\right\| d \theta$ :

$$
\begin{aligned}
e_{k+1}(t)= & e_{k}(t)+y_{k}(t)-y_{k+1}(t) \\
= & e_{k}(t)+C x_{k}(t)+D u_{k}(t)-\varphi_{k, h}(t) \\
& -C x_{k+1}(t)-D u_{k+1}(t)+\varphi_{k+1, h}(t) \\
= & e_{k}(t)-C\left(x_{k+1}(t)-x_{k}(t)\right) \\
& -D\left(u_{k+1}(t)-u_{k}(t)\right) \\
& +\left(\varphi_{k+1, h}(t)-\varphi_{k, h}(t)\right) \\
= & e_{k}(t)-C\left(x_{k+1}(t)-x_{k}(t)\right)-D M e_{k}(t) \\
& +D \psi_{k, h}(t)\left(x_{k+1}(0)-x_{k}(0)\right) \\
& +\left(\varphi_{k+1, h}(t)-\varphi_{k, h}(t)\right) \\
= & (I-D M) e_{k}(t)-C\left(x_{k+1}(t)-x_{k}(t)\right), \\
\| & \|I-D M\|\left\|e_{k}(t)\right\| \\
& +\|C\|\left\|x_{k+1}(t)-x_{k}(t)\right\| \\
\leq & \|I-D M\|\left\|e_{k}(t)\right\|+\|C\| e^{\left(1+l_{g} / l_{f}\right) T} \\
& +\int_{0}^{t}\|M\|\left\|e_{k}(\theta)\right\| d \theta . \\
(t) \| \leq &
\end{aligned}
$$

Using Lemma 1 and multiplying both sides of the above inequality (14) by $e^{-\lambda t}$ and taking the $\lambda$-norm, we have

$$
\begin{aligned}
\left\|e_{k+1}(t)\right\|_{\lambda} & \\
\leq & \|I-D M\|\left\|e_{k}(t)\right\|_{\lambda} \\
& +\frac{\|C\|\|M\| e^{\left(1+l_{g} / l_{f}\right) T}}{\lambda}\left\|e_{k}(t)\right\|_{\lambda} \\
= & \left(\|I-D M\|+\frac{\|C\|\|M\| e^{\left(1+l_{g} / l_{f}\right) T}}{\lambda}\right)\left\|e_{k}(t)\right\|_{\lambda} .
\end{aligned}
$$

Thus, condition (10) can guarantee $(\|I-D M\|+$ $\left.\|C\|\|M\| e^{\left(1+l_{g} / l_{f}\right) T} / \lambda\right)<1$ by selecting $\lambda$ sufficiently large, so we have $\lim _{k \rightarrow \infty}\left\|e_{k}(t)\right\|_{\lambda}=0$ for any $t \in[h, T]$. It follows from the equivalence of norms; we get that $\lim _{k \rightarrow \infty}\left\|e_{k}(t)\right\|=0$.

$$
\text { For any } t \in[0, h] \text {, }
$$

$$
\begin{aligned}
x_{k+1}( & t)-x_{k}(t) \\
= & \int_{0}^{t}\left(f\left(\theta, x_{k+1}(\theta)\right)-f\left(\theta, x_{k}(\theta)\right)\right) d \theta \\
& +\int_{0}^{t}\left(g\left(\theta, x_{k+1}(\theta-\tau)\right)-g\left(\theta, x_{k}(\theta-\tau)\right)\right) d \theta \\
& +\int_{0}^{t} M e_{k}(\theta) d \theta \\
& -\left(x_{k+1}(0)-x_{k}(0)\right)\left(\int_{0}^{t} \psi_{k, h}(\theta) d \theta-1\right),
\end{aligned}
$$$$
\left\|x_{k+1}(t)-x_{k}(t)\right\|
$$$$
\leq l_{f} \int_{0}^{t}\left\|x_{k+1}(\theta)-x_{k}(\theta)\right\| d \theta
$$$$
+l_{g} \int_{0-\tau}^{t-\tau}\left\|x_{k+1}(\theta)-x_{k}(\theta)\right\| d \theta
$$$$
+\int_{0}^{t}\|M\|\left\|e_{k}(\theta)\right\| d \theta
$$$$
+\left\|x_{k+1}(0)-x_{k}(0)\right\|\left\|\int_{0}^{t} \psi_{k, h}(\theta) d \theta-1\right\|
$$$$
\leq l_{f} \int_{0}^{t}\left\|x_{k+1}(\theta)-x_{k}(\theta)\right\| d \theta
$$$$
+l_{g} \int_{0-\tau}^{t-\tau}\left\|x_{k+1}(\theta)-x_{k}(\theta)\right\| d \theta
$$$$
+\int_{0}^{t}\|M\|\left\|e_{k}(\theta)\right\| d \theta+\eta
$$

where $\eta=\sup _{t \in[0, h]}\left(\left\|x_{k+1}(0)-x_{k}(0)\right\|\left\|\int_{0}^{t} \psi_{k, h}(\theta) d \theta-1\right\|\right)$. It is easy to know that

$$
\begin{aligned}
& \left\|x_{k+1}(t)-x_{k}(t)\right\| \\
& \quad \leq e^{\left(1+l_{g} / l_{f}\right) t}\left(\int_{0}^{t}\|M\|\left\|e_{k}(\theta)\right\| d \theta+\eta\right)
\end{aligned}
$$

by using Lemma 2. 
Then

$$
\begin{aligned}
\left\|e_{k+1}(t)\right\| \leq & \|I-D M\|\left\|e_{k}(t)\right\| \\
& +\|C\|\left\|x_{k+1}(t)-x_{k}(t)\right\| \\
\leq & \|I-D M\|\left\|e_{k}(t)\right\| \\
& +\|C\| e^{\left(1+l_{g} / l_{f}\right) T}\left(\int_{0}^{t}\|M\|\left\|e_{k}(\theta)\right\| d \theta\right) \\
& +\|C\| e^{\left(1+l_{g} / l_{f}\right) T} \eta .
\end{aligned}
$$

Using Lemma 1 and multiplying both sides of the above inequality by $e^{-\lambda t}$ and taking the $\lambda$-norm, we have

$$
\begin{aligned}
& \left\|e_{k+1}(t)\right\|_{\lambda} \\
& \quad \leq\left(\|I-D M\|+\frac{\|C\|\|M\| e^{\left(1+l_{g} / l_{f}\right) T}}{\lambda}\right)\left\|e_{k}(t)\right\|_{\lambda}+\eta \\
& \quad=\sigma\left\|e_{k}(t)\right\|_{\lambda}+\eta,
\end{aligned}
$$

where $\sigma=\|I-D M\|+\|C\|\|M\| e^{\left(1+l_{g} / l_{f}\right) T} / \lambda$ :

$$
\left\|e_{k+1}(t)\right\|_{\lambda}+\frac{\eta}{\sigma-1} \leq \sigma\left(\left\|e_{k}(t)\right\|_{\lambda}+\frac{\eta}{\sigma-1}\right) .
$$

Imitating the above proof, the result $\lim _{k \rightarrow \infty}\left\|e_{k}(t)\right\|_{\lambda}=0$ for any $t \in[h, T]$ is obtained by selecting $\lambda$ sufficiently large. So it is true that $\left\|e_{k}(t)\right\|$ is bounded on $t \in[0, h]$.

Remark 4. When the number of iterations $k \rightarrow \infty$ and $[h, T] \rightarrow[0, T]$, the tracking error satisfies that $\left\|e_{k}(t)\right\| \rightarrow 0$ on $t \in[0, T]$ for arbitrary initial state $x_{k}(0)$.

System (8) is

$$
\begin{aligned}
\dot{x}_{k}(t)= & f\left(t, x_{k}(t)\right)+g\left(t, x_{k}(t-\tau(t))\right)+u_{k}(t), \\
u_{k+1}(t)= & u_{k}(t)+M(t) e_{k}(t) \\
& -\psi_{k, h}(t)\left(x_{k+1}(0)-x_{k}(0)\right), \\
y_{k}(t)= & C(t) x_{k}(t)+D(t) u_{k}(t)-\varphi_{k, h}(t), \\
\varphi_{k+1, h}(t)= & \varphi_{k, h}(t)-D(t) \psi_{k, h}(t)\left(x_{k+1}(0)-x_{k}(0)\right),
\end{aligned}
$$

where the delay $\tau(t)$ satisfies $0<\dot{\tau}(t) \leq \gamma<1$.

Similar to the proof of Theorem 3, inequality (14) is written as

$$
\begin{gathered}
\left\|e_{k+1}(t)\right\| \leq\|I-D(t) M(t)\|\left\|e_{k}(t)\right\|+\|C(t)\| \\
\cdot\|M(t)\| e^{\left(1+(1-\gamma) l_{g} / l_{f}\right) T} \cdot \int_{0}^{t}\left\|e_{k}(\theta)\right\| d \theta \\
\left\|e_{k+1}(t)\right\|_{\lambda} \leq(\|I-D(t) M(t)\| \\
\left.+\frac{\|C(t)\|\|M(t)\| e^{\left(1+(1-\gamma) l_{g} / l_{f}\right) T}}{\lambda}\right)\left\|e_{k}(t)\right\|_{\lambda} .
\end{gathered}
$$

Then we have the following.
Theorem 5. For system (21) and a given reference $y_{d}(t)$, if there exist matrices $M(t), C(t)$, and $D(t)$ and functions $\psi_{k, h}(t)$ and $\varphi_{k, h}(t)$ such that $\|C(t)\|\|M(t)\|$ is bounded and $\| I-$ $D(t) M(t) \| \leq \rho<1$, where $\rho$ is a constant, then system (21) with the iterative learning control law can guarantee that $\left\|y_{k}(t)-y_{d}(t)\right\|$ is bounded but $y_{k}(t)$ cannot track $y_{d}(t)$ on $t \in[0, h]$ and $\lim _{k \rightarrow \infty} y_{k}(t)=y_{d}(t)$ on $t \in[h, T]$ for arbitrary initial state $x_{k}(0)$.

When $y_{k}(t)=s\left(t, x_{k}(t), u_{k}(t)\right)-\varphi_{k, h}(t)$ and $s\left(t, x_{k}(t)\right.$, $\left.u_{k}(t)\right)$ satisfies

$$
\begin{aligned}
& 0<\delta_{1} I<s_{u}=\frac{\partial s\left(x_{k}(t), u_{k}(t)\right)}{\partial u_{k}(t)} \leq \delta_{2} I, \\
& 0<\delta_{3} I<s_{x}=\frac{\partial s\left(x_{k}(t), u_{k}(t)\right)}{\partial x_{k}(t)} \leq \delta_{4} I,
\end{aligned}
$$

it is easy to obtain that

$$
\begin{aligned}
& s\left(t, x_{k+1}(t), u_{k+1}(t)\right)-s\left(t, x_{k}(t), u_{k}(t)\right) \\
& =s_{x}(\zeta)\left(x_{k+1}(t)-x_{k}(t)\right) \\
& \quad+s_{u}(\zeta)\left(u_{k+1}(t)-u_{k}(t)\right),
\end{aligned}
$$

where $\zeta \in\left[x_{k}(t)+\omega\left(x_{k+1}(t)-x_{k}(t)\right), u_{k}(t)+\omega\left(u_{k+1}(t)-u_{k}(t)\right)\right]$, $\omega \in(0,1)$.

Consider the following system:

$$
\begin{aligned}
\dot{x}_{k}(t)= & f\left(t, x_{k}(t)\right)+g\left(t, x_{k}(t-\tau)\right)+u_{k}(t), \\
u_{k+1}(t)= & u_{k}(t)+M e_{k}(t) \\
& -\psi_{k, h}(t)\left(x_{k+1}(0)-x_{k}(0)\right), \\
y_{k}(t)= & s\left(t, x_{k}(t), u_{k}(t)\right)-\varphi_{k, h}(t), \\
\varphi_{k+1, h}(t)= & \varphi_{k, h}(t)-s_{u} \psi_{k, h}(t)\left(x_{k+1}(0)-x_{k}(0)\right) .
\end{aligned}
$$

Similar to the proof of Theorem 3, we get

$$
\begin{aligned}
& \left\|e_{k+1}(t)\right\|_{\lambda} \\
& \quad \leq\left(\left\|I-s_{u} M\right\|+\frac{\left\|s_{x}\right\|\|M\| e^{\left(1+l_{g} / l_{f}\right) T}}{\lambda}\right)\left\|e_{k}(t)\right\|_{\lambda} .
\end{aligned}
$$

So we have the following result.

Theorem 6. For system (25) and a given reference $y_{d}(t)$, if conditions (9) are true and there exist matrix $M$ and functions $\psi_{k, h}(t)$ and $\varphi_{k, h}(t)$ such that $\int_{0}^{t} \psi_{k, h}(\theta) d \theta=1, t>h,\left\|s_{x}\right\|$ is bounded, $\max \left(\left\|I-\delta_{1} M\right\|,\left\|I-\delta_{2} M\right\|\right) \leq \rho<1$, where $\rho$ is a constant, then system (25) with the iterative learning control law can guarantee that $\lim _{k \rightarrow \infty} y_{k}(t)=y_{d}(t)$ is bounded but $y_{k}(t)$ cannot track $y_{d}(t)$ on $t \in[0, h]$ and $\lim _{k \rightarrow \infty} y_{k}(t)=y_{d}(t)$ on $t \in[h, T]$ for arbitrary initial state $x_{k}(0)$. 


\section{Numerical Example}

For further illustration, we consider the following system:

$$
\begin{aligned}
& \dot{x}_{k}(t)= 0.8 \cos ^{2}\left(x_{k}(t)\right) \\
&-0.5\left(\left|x_{k}(t-1)+1\right|-\left|x_{k}(t-1)-1\right|\right) \\
&+u_{k}(t), \\
& u_{k+1}(t)=u_{k}(t)+0.9 e_{k}(t) \\
&-\psi_{k, h}(t)\left(x_{k+1}(0)-x_{k}(0)\right), \\
& y_{k}(t)= \tanh \left(2 x_{k}(t)+0.9 u_{k}(t)\right)-\varphi_{k, h}(t), \\
& \varphi_{k+1}(t)= \varphi_{k}(t)-0.9 \psi_{k, h}(t)\left(x_{k+1}(0)-x_{k}(0)\right),
\end{aligned}
$$

where $M=0.9$ and

$$
\psi_{k, h}(t)= \begin{cases}\frac{\pi}{2 \times 0.5} \cos \left(\frac{\pi}{2 \times 0.5} t\right), & t \in[0,0.5), \\ 0, & t \in[0.5,5],\end{cases}
$$

taking the reference $y_{d}(t)=\sin t+1$.

From the above numerical example, it can be easily proved that the conditions of Theorem 6 are satisfied.

\section{Conclusion}

In this paper, considering the iterative learning control problem for nonlinear systems with delays, the novel sufficient conditions for robust convergence of the tracking error have been addressed.

\section{Competing Interests}

The author declares that there are no competing interests.

\section{Acknowledgments}

This work is supported by the National Natural Science Foundation of China (11071141), the Natural Science Foundation of Shandong Province of China (ZR2011AL018, ZR2011AQ008), and a Project of Shandong Province Higher Educational Science and Technology Program (J13LI02, J11LA06).

\section{References}

[1] S. Arimoto, S. Kawamura, and F. Miyazaki, "Bettering operation of Robots by learning," Journal of Robotic Systems, vol. 1, no. 2, pp. 123-140, 1984.

[2] H.-S. Lee and Z. Bien, "A note on convergence property of iterative learning controller with respect to sup norm," Automatica, vol. 33, no. 8, pp. 1591-1593, 1997.

[3] Y. Chen, Z. Gong, and C. Wen, "Analysis of a high-order iterative learning control algorithm for uncertain nonlinear systems with state delays," Automatica, vol. 34 , no. 3, pp. 345353, 1998

[4] J.-X. Xu and Y. Tan, "A composite energy function-based learning control approach for nonlinear systems with timevarying parametric uncertainties," IEEE Transactions on Automatic Control, vol. 47, no. 11, pp. 1940-1945, 2002.
[5] A. Tayebi, "Adaptive iterative learning control for robot manipulators," Automatica, vol. 40, no. 7, pp. 1195-1203, 2004.

[6] R. H. Chi, Z. S. Hou, and J. X. Xu, "Adaptive ILC for a class of discrete-time systems with iteration-varying trajectory and random initial condition," Automatica, vol. 44, no. 8, pp. $2207-$ 2213, 2008.

[7] C.-J. Chien, "A combined adaptive law for fuzzy iterative learning control of nonlinear systems with varying control tasks," IEEE Transactions on Fuzzy Systems, vol. 16, no. 1, pp. 4051, 2008.

[8] Y.-C. Wang and C.-J. Chien, "Decentralized adaptive fuzzy neural iterative learning control for nonaffine nonlinear interconnected systems," Asian Journal of Control, vol. 13, no. 1, pp. 94-106, 2011.

[9] J.-X. Xu, D. Huang, V. Venkataramanan, and T. C. T. Huynh, "Extreme precise motion tracking of piezoelectric positioning stage using sampled-data iterative learning control," IEEE Transactions on Control Systems Technology, vol. 21, no. 4, pp. 1432-1439, 2013.

[10] Q. Lv, Y.-C. Fang, and X. Ren, "Iterative learning control for accelerated inhibition effect of initial state random error," Acta Automatica Sinica, vol. 40, no. 7, pp. 1295-1302, 2014.

[11] J.-M. Wei, Y.-A. Hu, and M.-M. Sun, "Observer-based adaptive iterative learning control for a class of nonlinear time delay systems with input saturation," Mathematical Problems in Engineering, vol. 2015, Article ID 645161, 19 pages, 2015.

[12] J. Li and J. Li, "Iterative learning control approach for a kind of heterogeneous multi-agent systems with distributed initial state learning," Applied Mathematics and Computation, vol. 265, pp. 1044-1057, 2015.

[13] L. Yan and J. Wei, "Fractional order nonlinear systems with delay in iterative learning control," Applied Mathematics and Computation, vol. 257, pp. 546-552, 2015.

[14] H. Cai, Y. Huang, J. Du, T. Tang, D. Zuo, and J. Li, "Iterative learning control with extended state observer for telescope system," Mathematical Problems in Engineering, vol. 2015, Article ID 701510, 8 pages, 2015.

[15] S. S. Ge, F. Hong, and T. H. Lee, "Robust adaptive control of nonlinear systems with unknown time delays," Automatica, vol. 41, no. 7, pp. 1181-1190, 2005.

[16] C. C. Hua, G. Feng, and X. P. Guan, "Robust controller design of a class of nonlinear time delay systems via backstepping method," Automatica, vol. 44, no. 2, pp. 567-573, 2008.

[17] X. D. Ye, "Adaptive stabilization of time-delay feedforward nonlinear systems," Automatica, vol. 47, no. 5, pp. 950-955, 2011.

[18] J. Na, "Adaptive prescribed performance control of nonlinear systems with unknown dead zone," International Journal of Adaptive Control and Signal Processing, vol. 27, no. 5, pp. 426446, 2013.

[19] Z.-Y. Sun and Y.-G. Liu, "Adaptive control design for a class of uncertain high-order nonlinear systems with time delay," Asian Journal of Control, vol. 17, no. 2, pp. 535-543, 2015.

[20] Q.-L. Zhang, "Synchronization of multi-chaotic systems via ring impulsive control," Control Theory \& Applications, vol. 27, no. 2, pp. 226-232, 2010.

[21] Q. Zhang, "Synchronization of multi-chaotic systems with ring and chain intermittent connections," Applied Mechanics and Materials, vol. 241-244, pp. 1081-1087, 2013.

[22] Q. Zhang, "A class of vector Lyapunov functions for stability analysis of nonlinear impulsive differential systems," Mathematical Problems in Engineering, vol. 2014, Article ID 649012, 9 pages, 2014. 
[23] Q. Zhang, "Matrix measure with application in quantized synchronization analysis of complex networks with delayed time via the general intermittent control," Annals of Applied Mathematics, vol. 31, no. 1, pp. 115-126, 2015.

[24] W. S. Chen and L. Zhang, "Adaptive Iterative learning control for nonlinearly parameterized systems with unknown timevarying delays," International Journal of Control, Automation and Systems, vol. 8, no. 2, pp. 177-186, 2010.

[25] J.-M. Wei, Y.-A. Hu, and M.-M. Sun, "A new AILC for a class of nonlinearly parameterized systems with unknown delays and input dead-zone," Journal of Applied Mathematics, vol. 2014, Article ID 238018, 14 pages, 2014.

[26] J.-M. Wei, Y.-A. Hu, and M.-M. Sun, "Adaptive iterative learning control for a class of nonlinear time-varying systems with unknown delays and input dead-zone," IEEE/CAA Journal of Automatica Sinica, vol. 1, no. 3, pp. 302-314, 2014.

[27] M.-X. Sun and B.-J. Huang, Iterative Learning Control, National Defence Industry Press, Beijing, China, 1999.

[28] R. P. Agarwal, S. Deng, and W. Zhang, "Generalization of a retarded Gronwall-like inequality and its applications," Applied Mathematics and Computation, vol. 165, no. 3, pp. 599-612, 2005. 


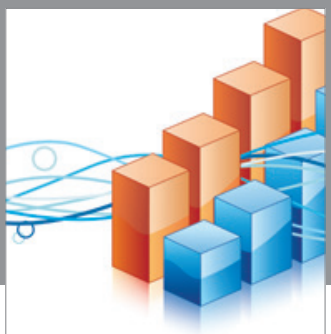

Advances in

Operations Research

vatem alat4

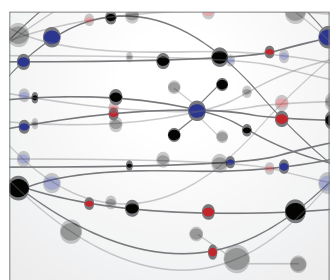

\section{The Scientific} World Journal
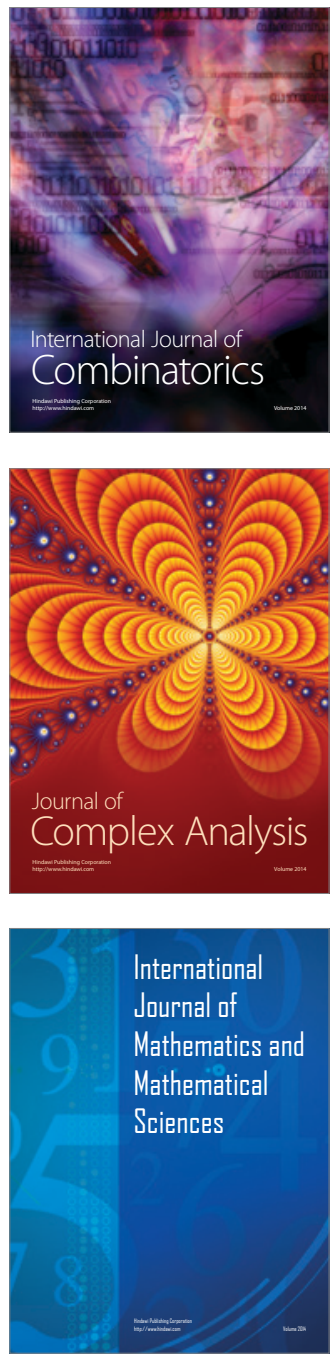
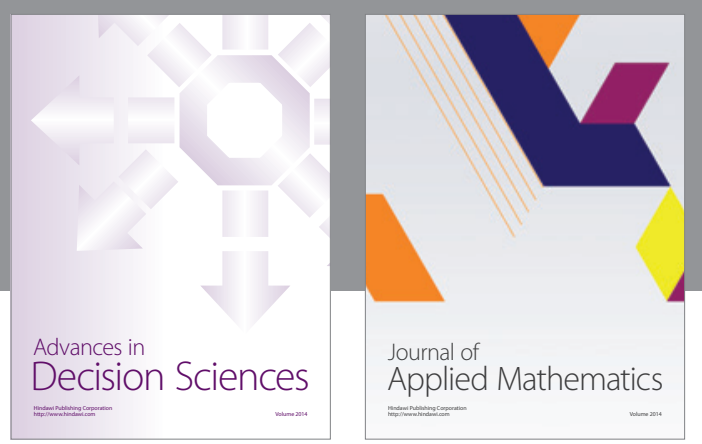

Algebra

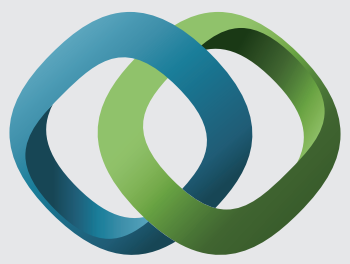

\section{Hindawi}

Submit your manuscripts at

http://www.hindawi.com
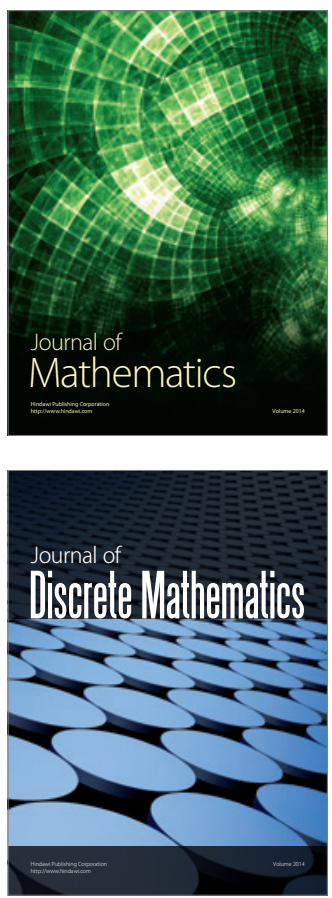

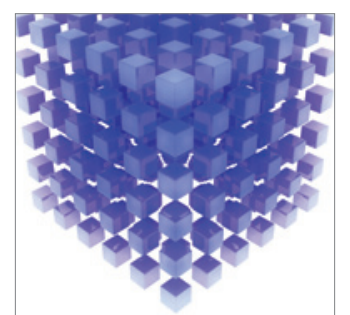

Mathematical Problems in Engineering
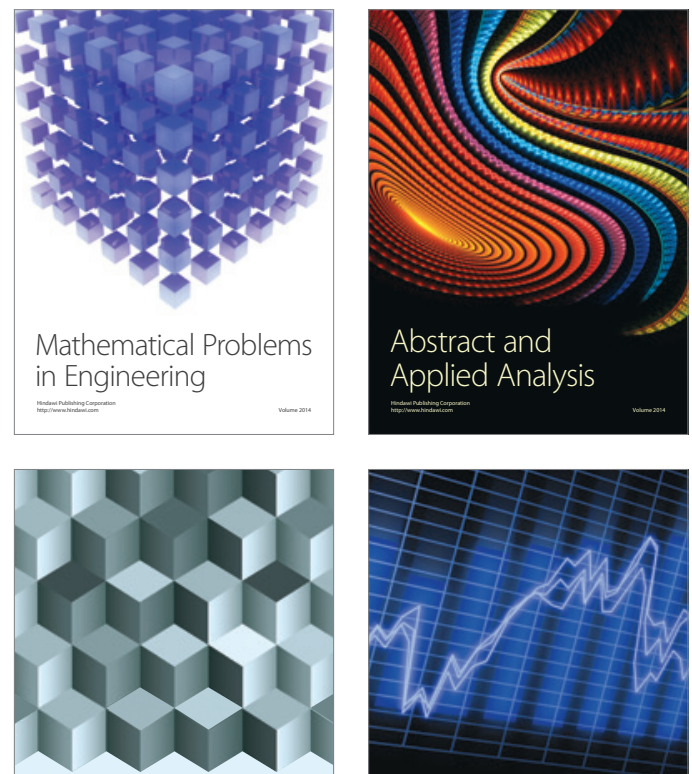

Journal of

Function Spaces

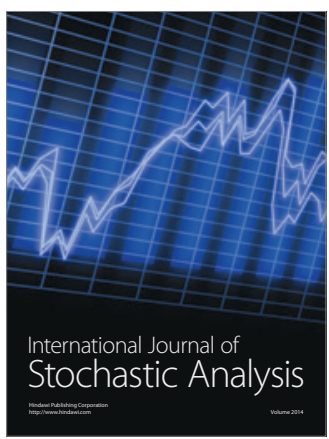

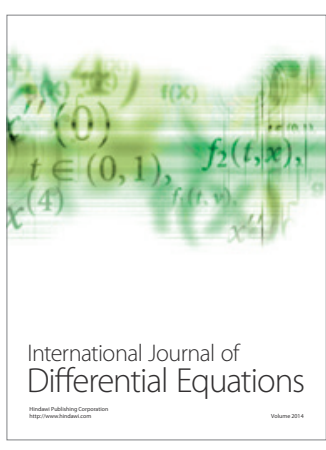
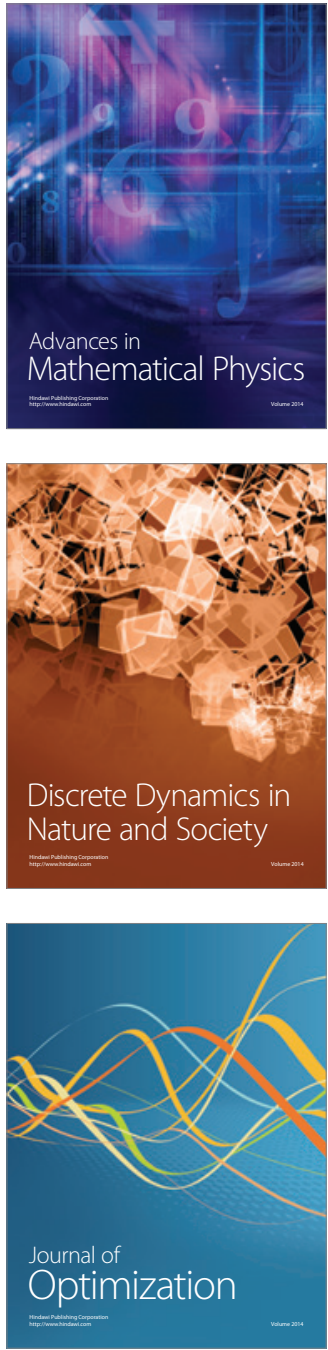